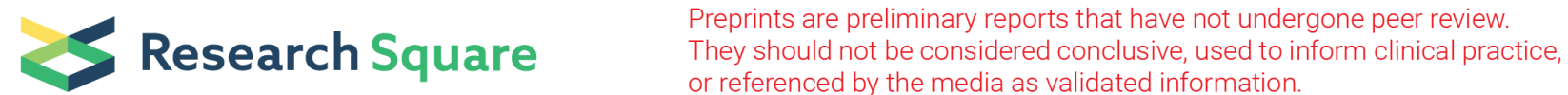

\section{Modelling the temporal and spatial wind energy trend in the Caspian Sea}

\section{Milad Rahime ( $\nabla$ miladrhime@yahoo.com )}

Postgraduate Faculty of Natural Resources, Tarbiat Modarres University https://orcid.org/0000-00023045-9854

\section{Mehdi Gholamalifard}

Assistant Professor of Environmental Science, Faculty of Natural Resources, Tarbiat Modarres

University

\section{Akbar Rashidi Ebrahim Hesari}

Assistant Professor of Marine Physics Department, Faculty of Marine Sciences, Tarbiat Modares University

\section{Article}

Keywords: Offshore wind energy, QuikSCAT, RapidSCAT, Caspian Sea, Trend Ecosystem

Posted Date: October 7th, 2020

DOI: https://doi.org/10.21203/rs.3.rs-84580/v1

License: (c) (1) This work is licensed under a Creative Commons Attribution 4.0 International License.

Read Full License 


\section{Abstract}

The oceans and seas have huge areas of the planet. The ecosystem services that can be obtained from these resources are very diverse and with potential one of these sources is wind power. As a result, the Caspian Sea is widespread with a fragile ecosystem. Which seems to be the right choice for the development of this industry. Therefore, for modeling the wind energy of the Caspian Sea, the data from the ERA-Intrem for 1980 to 2015 combined with QuickScat and RapidScat remote sensing data. The modeling results showed a power density of $173 \mathrm{~W} / \mathrm{m} 2$, concentration density in the series process showed that $67 \%$ of the Caspian Sea area has a decreasing trend, the rate of this sea change for the entire period from 1980 to 2015 was $2.1 \mathrm{~W} / \mathrm{m} 2$. These changes in the northern part of the Caspian Sea have a higher rate than other parts. The sea is affected by climate change.

\section{Introduction}

Today's energy is considered as a factor in the well-being of a society, in the last three decades, energy consumption has reached three and a half times [1].In the meantime, electricity is one of the most important energy sources in the energy basket. Reducing the resources and limitations of terrestrial lands today has brought more attention to ecosystem services and sea and ocean goods[2].In this regard, marine energy is one of the cleanest and most energy-intensive ones. In terms of the specific characteristics of this energy development and utilization of wind energy today is thriving. The importance of using wind energy in 2015, according to a report, has been accompanied by an increase of $22 \%$ in the installation of wind turbines, which has an offshore turbine with 4.3 gig watts the highest percentage increase compared to previous years. Britain, Germany, the United States, Denmark, India and Spain are among the most active countries in the field of wind energy for electricity generation [3]. Identifying and evaluating spatial potential in the process of uncertainty reduction and uncertainty for the development of wind farms is vital [4]. Today, there are various quantitative and qualitative sources and methods for detecting offshore wind and its abilities. Which has remote sensing and numerical models with the highest degree of time and space discipline[5] there are several parameters in predicting suitable places for creating wind farms. Wind as the most effective factor in the development of wind farms has important characteristics such as speed and direction[6]. Wind resource is highly variable, It should be noted that along with the capacity of more offshore wind farms, the cost of energy generation and maintenance will be higher than wind power plants[7]. In the following, given that the natural environment of the situation will not be constant, given that the natural environment of the situation will not be constant, but the marine environment has a cycle of changes that are under the influence of various parameters[8]. With regard to wind energy sources, there has been a trend that has threatened investment in this sector. Therefore, reviewing the process of change is very important in identifying places of change in future investments and assurances[9, Ch. 2]. These concerns are increasing in closed seas where there is no accurate information about them and closes the path to development[10][11]. The Caspian Sea is one sea closed According to the literature review, The study of low have been conducted on the Caspian Sea[12]. The study [13]was conducted on all the water bodies of the world except the two Black and 
Caspian seas. Their data was from various sources such as NCEP, ECMWF and QuickScat. The results of their research indicated that the wind energy was increased from 20 to 45 megawatts per kilometer to increase one meter deep of the sea, the average power density was $478 \mathrm{~W} / \mathrm{m}^{2}$. The study (Onea et al) in 2015 was conducted on the assessment of the waves and wind energy of the Caspian Sea, This study studied the spatial data of ERA-Intrem and the satellite data with buoys in this wind field at 14 points for 10 years. The results of the seasonal variations on wind energy and wind speed were significant. Eventually, the result of this study was the density of wind energy in the range of 93 to $356 \mathrm{~W} / \mathrm{m}^{2}$ [8]. Recent study (Kamranzad et al) 2017 the mapping of southern Caspian potentials for wind and wave energy was studied using ECMWF numerical model data for 2009-2015. In this study, 100 points were used. The power density in the Southern Caspian is less than $100 \mathrm{~W} / \mathrm{m}^{2}$ [14]. In the following (Osinowo et al) 2017 estimate the Taiwanese offshore wind power density at $300 \mathrm{~W} / \mathrm{m}^{2}$. Although the process of energy changes has been increasing indefinitely but in the spring, the trend has been reduced by -0.68 watts per square meter[15].

Therefore, the objective of this study is to assess the time- spatial of available wind resources in the first step and in the second step calculate the energy, at the end of the study trend of changing the wind energy is the ecology of this sea

\section{Data And Methods}

\section{2-1 Data and study area}

Caspian Sea The world's largest closed sea basin has its own specific geographical, climate and a special ecological and political significance with a 7,000-kilometer seabed of five Russia and Kazakhstan in the north, Turkmenistan in the east, Azerbaijan in the west and Iran in the south based on the topographic features of the Caspian Sea is divided into 3 parts[16], shown in Figure (1).

Due to the structural constraints, the amount of information from offshore is very limited this method is used to study model data and to measure remote Sensing as a common practice[17]. Since the accuracy and accuracy of the data are evaluated by previous studies and all believe in the correctness of ECMWF[18][19][20], this study will also combine Remote Sensing with QuickScat, RapidScat and numerical measurement data. ERA-Intrem data was used with a spatial accuracy of 0.75 degrees at a time of 6 hours for the 36-year period from 01/01/1980 to 01/01/2017. To assess the accuracy of the data model in place and time satellite images and buoys were used which results show fit suitability. The accuracy of the wind speed computed by the model was evaluated through a conventional statistical analysis [21] with the following equation (1): 
$C=\frac{\sum_{i=1}^{n}\left(X_{i}-X\right)\left(I_{i}-Y^{-}\right)}{\sqrt{\sum_{i=1}^{n}\left(X_{i}-X\right)^{2}} \cdot \sqrt{\sum_{i=1}^{n}\left(I_{i}-Y^{-}\right)^{2}}}$

Bais $=X-Y$

$\operatorname{RMSE}=\sqrt{\frac{\sum_{i=1}^{n}\left(\mathrm{y}_{i}-x_{i}\right)^{2}}{n}}$

\section{2-2 Power density}

A predominant energy assessment is an elemental site of wind energy projects. Density of energy concentration the design of the site and turbine blade is very effective. In order to check the amount of energy per unit area and its fit for construction of wind power sites[22], the equation can be rewritten and easily used (2):

$$
P D=\frac{1}{2} \rho \sum_{j=1}^{n}\left(f\left(v_{j}\right) \cdot \mathrm{v}_{j}{ }^{3}\right)
$$

In the PD equation, the power density of a given area is given in Watts Sq. M $\rho$ also shows the density of the air $F\left(\mathrm{v}_{\mathrm{j}}\right)$ and $\left(\mathrm{v}_{\mathrm{j}}\right)$ respectively indicate the probability of wind blowing in Specific speed and wind speed.

Usually for modeling wind energy various statistical functions such as the Weibull and Ryleigh function are used; the accuracy of these statistical functions depends on the type and accuracy of their parameters the accuracy of these statistical functions depends on the type and accuracy of their parameters there are several methods to calculate the parameters of these functions That the method of standard deviation, moment probability, most probability of neighborhood, energy distribution is most used[6, Ch. 3] In the wind turbine studies, the Weibull function has the highest application accuracy and therefore equation (3) represents the probability density function of Weibull.

$$
f(v)=\frac{\kappa}{\lambda}\left(\frac{v}{\lambda}\right)^{\kappa-1} e^{-\left(\frac{v}{2}\right)^{k}}
$$

In the equation $K, \lambda$, respectively, represent the shape and scale factors Form factor is a dimensionless number Which is a way of showing the variability of wind speed In fact, in the probability distribution plots, the slope of the function line is affected In fact, the higher the shape factor, the lower the wind's variability, On the other said, the scale factor is expressed on the basis of $\mathrm{m} / \mathrm{s}^{-1} \mathrm{In}$ fact, this factor indicates the concentration of wind speed in a certain range. A small scale factor helps to increase the probability of wind speed in other words Changes to this factor affect the amount of the base curvature scale e is equal to the number of nippers[23, Ch. 2] figure (2). And $f(v), v$ represent probability wind speed and wind speed, respectively. 
Each natural environment does not always have a constant condition, marine environments have a circle of changes are influenced by various parameters. Wind energy is a trend that has threatened investment in this sector. Check the trend in order to detect changes in places, for future, it is very important investments.2-3 Time Sires

\section{2-3-1 Mann-Kendall}

The Mann-Kendall index is a nonlinear index and the degree to which an individual continuously increases or decreases and its range is between +1 and -1 ; Positive value indicates that the trend is constantly increasing and the negative value of the trend has been steadily declining and zero also indicates the absence of the trend. Man-Kendall is defined as follows equation (4):

$$
\begin{gathered}
S=\sum_{i=1}^{n-1} \sum_{j=i+1}^{n} \operatorname{sign}\left(x_{i}-x_{j}\right) \\
\operatorname{sign}\left(x_{i}-x_{j}\right)=\left\{\begin{array}{lll}
1 & \text { if } & x_{i}-x_{j}<0 \\
0 & \text { if } & x_{i}-x_{j}=0 \\
1 & \text { if } & x_{i}-x_{j}>0
\end{array}\right.
\end{gathered}
$$

Where $n$ is the series for a long time, and $x_{i}$ and $x_{j}$ are observations at time $i$ and $j$.

For the analysis of the Caspian Sea, we categorized 1 * 1 degrees indexes. Where $n$ is the series for a long time, and $x_{i}$ and $x_{j}$ are observations at time $i$ and $j$.

\section{Results}

\section{3-1 Wind data resource evaluation}

The results of the correlation between the measurement resources and the numerical models are shown in Fig (3\&4). It shows the effect of environmental changes on data correlation. But the total amount of data correlation in the offshore is increasing, as the impact of environmental factors on the characteristics of data and uncertainties is decreasing[24] Spatial analysis in the Caspian Sea shows that spatial correlation in the south of the Caspian will be divided into two parts. The northwest portion, which is the deepest part of the Caspian basin, Correlation is higher than the Southeast have. This part is due to the special geographic and the reduction of water depth the difference between the two sources increases and has the least correlation [13] In general table (1) show statistics for every parts Caspian Sea, the southern Caspian has a correlation coefficient of 0.92 for the QuickScat sensor and a correlation coefficient of 0.48 for the RapidScat sensor existence of geographic conditions and wind speed more in the middle Caspian is a factor that the correlation coefficient for QuickScat and RapidScat is 0.93 and 0.76. The greatest reduction in correlation is seen in the middle boundary of the northern Caspian that geographical condition affects this correlation. With increasing geographic length in the north of the Caspian, the specific features of this section, in terms of geographic form and depth reduction of the Caspian Sea and long freezing, have reduced the correlation of data and increased uncertainty in this 
section, resulting in a correlation coefficient for the QuickScat sensor to be less than 0.53 [25] , this restriction was prevented from providing information for the RapidScat.

Table 1: Statistical errors of observed satellite/ ECMWF

$10 \mathrm{~m}$ wind speed data comparison for the period of 2015 in the ECS: correlation coefficient (C.C), bias $(\mathrm{m} / \mathrm{s})$ and root mean square error (RMSE).

\begin{tabular}{|lllll|}
\hline Part & Stellate & RMSE & Bais & C.C \\
\hline North & Rapid Scat & - & - & - \\
\hline \multirow{2}{*}{ Mid } & Quick Scat & 0.76 & -0.53 & 0.53 \\
\hline \multirow{2}{*}{ South } & Rapid Scat & 0.27 & 0.27 & 0.76 \\
\hline & Quick Scat & 0.71 & -0.71 & 0.93 \\
\hline & Rapid Scat & 0.60 & 0.60 & 0.48 \\
\hline
\end{tabular}

\section{3-2 Wind speed and indicators}

The results of Figure (5) shows the average wind speed in the entire period of study. Wind speed is more intense with increasing distance from coast to offshore areas In general, the western and southern parts of the Caspian Sea have a lower wind speed. The wind speed in the 64 and 15 indexes is respectively 1.84 and $6.20 \mathrm{~m} / \mathrm{s}^{-1}$, respectively, with the lowest and the highest average wind speed, which is consistent with the results [20]. The average wind speed for the entire Caspian Sea is $4.83 \mathrm{~m} / \mathrm{s}^{-1}$. So we can conclude The Caspian Sea's wind regime has been influenced by three main factors: Regional atmospheric activity, topography of the coasts (mountains) and local currents affected by temperature differences between land and sea.

The mean monthly wind speed changes the results of seasonal variations in wind speed (fig 6) for different months indicate a slight spatial displacement in different months of the year in the southern part of the Caspian Sea. But what is clear Change the location of the centers with the highest wind speed between the northern and middle of the Caspian Sea, it moves over the four months (June, July, August and September) to the margin of the coast of the peninsula of the Caspian.

The increase in winter wind speed is in all three parts. March is the highest wind speed for the north, middle and south, respectively $(6.7,6.3$ and 4.5$)$. There is a decrease in wind speed from the warm season until late fall Therefore, unlike increasing the wind speed, the wind speed does not go down in a month for the most part but also for the middle and southern parts of July (4.3 and 6.3), while September has the lowest wind speed (4.9) for the northern segment (fig 7). The increase in winter wind speed is in all three parts March is the highest wind speed for the north, middle and south, respectively $(6.7,6.3$ and 4.5). There is a decrease in wind speed from the warm season until late fall Therefore, unlike increasing the wind speed, the wind speed does not go down in a month for the most part But also for the middle 
and southern parts of July (4.3 and 6.3), while September has the lowest wind speed (4.9) for the northern segment.

\section{3-3 Power density}

\section{3-3-1 Estimated annual power density}

The results of the average power density for the entire Caspian Sea for 36 years in Figure (8) show that the overall average energy in the Caspian Sea is $173 \mathrm{~W} / \mathrm{m}^{2}$. The present result, based on the reported amount (Scott et al) in 2010, reports low levels of power in the Caspian Sea relative to all of the water areas. But the distribution of wind energy in the Caspian Sea is not homogeneous, but varies across the sea. This energy on the northern and middle northern boundary is much higher than in other parts of the Caspian Sea between 250-300 W/ $\mathrm{m}^{2}$. Wind energy classification better reflects spatial and temporal changes in the higher classes located in the center of the middle section. More wind power in the South Caspian area classified as low (less than $100 \mathrm{~W} / \mathrm{m}^{2}$ ) is located. But the largest area of the Caspian Sea is the low class area of 250-200 with a total area of 126 thousand square kilometers With focus on central and northern part of the Caspian offshore been.

What follows from Fig. 9: The maximum capacity of the North Caspian in the winter of 1993 was 130 watts per square meter and the minimum in the winter of 2003 was $50.70 \mathrm{~W} / \mathrm{m}^{2}$. In the spring of 79.3 (max. 2000 and minus 1986), in summer, 65.9 (maximum 1998 and min 1999), autumn 84.64 (maximum 2001 and min. 2000), according to analyzes most fluctuations in the Caspian Sea Between 1998 and 2003.

The results are as shown in Fig. 10 represents a stable environment for middle Caspian According to the results of the peak winter energy equal to $130.38 \mathrm{~W} / \mathrm{m}^{2}$ has been modeled in 2010 And the minimum of 2003 is estimated at $64.25 \mathrm{~W} / \mathrm{m}^{2}$. The range for the spring was $43.74 \mathrm{~W} / \mathrm{m}^{2}$, with a peak in 1990 and a minimum of 1986. The summer season has an amplitude of $48.88 \mathrm{~W} / \mathrm{m}^{2}$ (maximum 1997 and minimum 1981 ) and for the fall this model is modeled at $69.23 \mathrm{~W} / \mathrm{m}^{2}$ (max. 2015 and $\mathrm{min} .2000$ ).

Figure (11) shows seasonal variations in power density for the southern Caspian. The results for the winter season indicate a range of changes of $33.4 \mathrm{~W} / \mathrm{m}^{2}$, the highest and the lowest in 1989 and 1995.The same range for the spring was equal to $72.22 \mathrm{~W} / \mathrm{m}^{2}$ (maximal 2004 and minus 1983), for the summer season, the range reached $24.45 \mathrm{~W} / \mathrm{m}^{2}$ (maximum 1997 and $\min 1994$ ). Finally, for the fall season, the simulation results indicate that the range of variations is $46.14 \mathrm{~W} / \mathrm{m}^{2}$ (the maximum is 2004 and the lowest of 2010). What is clear is that from 2010 to 2015 there is an increasing trend in the density of the Caspian Sea.

\section{3-4 Analysis of monthly time series}

The results of the wind velocity uniformity trend in the Caspian Sea (Figure 12.A) show wind speed increase in the northern Caspian Sea the focus of this increase is on index 9 and 10, but it is noteworthy 
this trend is very low and reaches the highest value in index 9 to 0.05 . On the opposite side of this trend, there is a dramatic decrease in the margins of the coast of Iran the focus of this trend is on indexes 62, 63 and 64.This slowdown can depend on the environmental conditions of the Caspian Sea, which can be seen near Langroud city.

The results of the man-Kendall statistics show there are increasing and decreasing trends for both shape and scale factors in the study area. Generally for the shape factor Indexes 67, 56 and 27 have the highest decreasing trend In contrast, the indexes 46,47 and 41 , with an incremental rate of $0.11,0.97$ and 0.97 respectively, will increase confidence. For the scale factor, the 62th, 63rd and 64th indexes also have the largest decreasing trend in the Caspian Sea overall. In the next ranks of indexes $46,47,45$ there is a decreasing trend of $-0.12,-0.11$ and -0.14 respectively. In general, there is no increase in the average Caspian Sea part from the individual pixels, they are in indexes 34 and 35 (Figure 12.B\&C). The results of this section with respect to the overall decreasing trend as the scale factor indicates the position of the focus is likely to be at lower speeds and reduced.

In the study area the increase and decrease in power density, however, the highest increase in power density in the southern Caspian is to the highest concentration around the coast zone near of Iran, with the 62,63 and 64 indexes. This section is consistent with the results of the Man-Kendall statistics for the scale factor in this indexes. Also, the highest decreasing trend in this statistic is observed in the northern Caspian in the 9th and 8th grades in the lower ranking in the index 53 in the southern part of the Caspian. In general, the Caspian Sea faces a declining trend in $66 \%$ of its area (Figure 12.D). These changes can be considered with the special status of the Caspian Sea.

Which, due to the climate change of the Caspian Sea in the northern part (this part of the sea is frozen in months from the year), has led to a decrease in the density of power during the period, Then also Astrakhan coast and beyond. in the center of the Caspian Sea (Caspian Border mid-South) are affected by the topography of the coastal zone and the mountains of the Caucasus have a very influential effect on the creation of high pressure shafts in this area. Therefore, with the climate change in this area and the reduction of sea-drought temperature differences, this part of the sea (indexes 46, 52 and 53) has been reduced by power density reduction. The results of the significant trend for power density indicate that the value of $p$-Value in indexes 62 and 63 is smaller than 0.05 , which indicates a significant trend for other parts of the Caspian Sea, this is larger than 0.05 , indicating no significant trend(Figure 12.E).

The results of the review of time series changes are shown using the linear trend process The North part index is 9,8 and 10 times the lowest which is a report of the monthly loss of power density in the area. But in general, the Caspian Sea has a linear trend of -0.14 for the entire time series. In the southern part this level was -0.045 , but it has a downward trend. Unlike the two mentioned, the Caspian middle 0.032 average power density linear trend is on the rise during the period. In this section, indexes 20, 23 and 29 are at the highest rate. The total power loss rate in the Caspian Sea for 36 years is equal to $2.1 \mathrm{~W} / \mathrm{m}^{2}$. This section was compared to report (Osinowo et al) 2017 for the Taiwan Sea, the Caspian Sea has a faster downtrend (Figure 12.F). 


\section{3-5 summarize the results}

It is known that uncertainties in the environment will not be resolved by statistics such as mean and median, It is also about the process of environmental change that shows the status of an environment in the long run and will be useful in future planning, this factor is less obvious in previous studies seems to be in the study of the pattern of wind energy pattern changes, the effect of shape factor and scale factors in long-term effects on the energy trend (Figure 13.A).Specifically, the decreasing trend of the scale factor with the trend of decreasing power density has been directly correlated; This means that reducing the scale factor reduces the height of the graph. In contrast, the incremental shape of the shape factor causes a negative skewness and the peak curve position is lowered at a higher probability for the wind speed.

The long-term potential of the environment in the dimension of the location and its changes in the dimension of time for the Caspian Sea are shown in (Figure 13.B). The results are shown despite high energy density in the northern Caspian, it is accompanied by a declining trend the focus of this decline is on index 9 . As noted in previous sections, this area seems to be affected by climate change. In the next step, indexes 46, 52 and 53 have a decreasing trend, interestingly, there are Azerbaijani power plants in this area which is not considered in the feasibility study of wind speed variations. But due to the trend in the southern Caspian Sea, this density is the lowest possible. This study specifies that indexes 21, 23 and 28 as the process is incremental, it has the highest density of power in the entire Caspian Sea, which has an ideal location for future developments. Figure 13.B shows distinct results from all past studies, which simultaneously show the environmental power and ambiguity of the environment this shape can be used more in the location of wind power plants.

\section{Conclusion}

In the present study, we investigated the location of two reference data and a numerical model for a closed sea despite the good overall correlation between the Caspian Sea, the data on spatial variations in terms of depth and distance from the coast is very effective in reducing accuracy and accuracy. In addition, the seasonal changes and wind speed increase will double this problem. According to the features mentioned above, this correlation of data for the middle and southern parts was significant at 0.93 and 0.92 for the mean of the total area. In contrast, due to the shape of the beaches and the low depths, northern climatic conditions of the northern basin do not show correlation of the data in the whole meaningful period. With this account, the model data, although lower than wind speeds, showed better reliability and spatial correlation.

The results of this study showed The time series for Weibull factors are highly dependent on the change in both components To the extent that by increasing the correlation of the form factor in indexes 46,45 and 41 , which indicates a stability increase Against the non-change of the scale factor, a probability report will be reported The same is true in the 62,63 and 64 indexes Overall, due to the overall decrease of the Caspian Sea scale factor this factor is more than a factor in the assessment of wind resources. In the 
whole of the Caspian Sea, the rate of change was $2.1 \mathrm{~W} / \mathrm{m}^{2}$. Similarly, this decrease is reflected in $66 \%$ of the total Caspian area. However, a significant statistic using only a small part of the South Caspian significant trend will be observed and show downturn has occurred in parts of the Caspian Sea, which is heavily influenced by the changing weather conditions. This change in the North Sea in the Volga River delta near the physically challenged layers and is icebound And also in the west of the middle reaches to the border of the southern part is affected by the mountains of the Caucasus. The increasing trend shows the density of $23 \%$ of the Caspian area, which shows the eastern part of the Caspian Sea and the southern coastline of the trend.

The results of this study for the power density showed that two-thirds of the area of this sea has a desirable power. By passing low latitudes to the north, the density of power is always increased, but this power is ultimately observed at the northern-central boundary of the Caspian, In fact, the Caspian Sea seems to be affected The Siberian High-Pressure Layer prevents the increase of wind speed and, consequently, power density.

\section{References}

[1] Anon, "Annual Energy Outlook 2016," Energy Inf. Adm., 2016.

[2] M. Busch, K. Gee, B. Burkhard, M. Lange, and N. Stelljes, "Conceptualizing the link between marine ecosystem services and human well-being: the case," no. 2005, pp. 1-14, 2011.

[3] G. W. E. Council, Global Wind 2015 Report: Annual Market Update. 2016.

[4] A. Mostafaeipour, "Feasibility study of offshore wind turbine installation in Iran compared with the world," Renew. Sustain. Energy Rev., vol. 14, no. 7, pp. 1722-1743, 2010.

[5] F. Pimenta, W. Kempton, and R. Garvine, "Combining meteorological stations and satellite data to evaluate the offshore wind power resource of Southeastern Brazil," pp. 1-13, 2008.

[6] M. Sathyajith, Wind Energy: Funamentals, Resource Analysis and Economics. 2006.

[7] E. I. Zountouridou, G. C. Kiokes, S. Chakalis, P. S. Georgilakis, and N. D. Hatziargyriou, "Offshore fl oating wind parks in the deep waters of Mediterranean Sea," Renew. Sustain. Energy Rev., vol. 51, pp. 433-448, 2015.

[8] F. Onea, A. Raileanu, and E. Rusu, "Evaluation of the Wind Energy Potential in the Coastal Environment of Two Enclosed Seas," vol. 2015, pp. 0-7, 2015.

[9] J. F. Manwell, C. N. Elkinton, A. L. Rogers, and J. G. McGowan, "Review of design conditions applicable to offshore wind energy systems in the United States," Renew. Sustain. Energy Rev., vol. 11, no. 2, pp. 210-234, 2007. 
[10] R. P. Signell et al., "Assessment of wind quality for oceanographic modelling in semi-enclosed basins," vol. 53, pp. 217-233, 2005.

[11] S. Hadadpour, H. Moshfeghi, E. Jabbari, and B. Kamranzad, "Wave hindcasting in Anzali, Caspian Sea: a hybrid approach," J. Coast. Res., vol. 65, no. 65, pp. 237-242, 2013.

[12] F. Manzano-Agugliaro, A. Alcayde, F. G. Montoya, A. Zapata-Sierra, and C. Gil, "Scientific production of renewable energies worldwide: An overview," Renew. Sustain. Energy Rev., vol. 18, pp. 134-143, 2013.

[13] S. B. Capps and C. S. Zender, "Estimated global ocean wind power potential from QuikSCAT observations, accounting for turbine characteristics and siting," J. Geophys. Res. Atmos., vol. 115, no. 9, pp. 1-13, 2010.

[14] G. Amirinia, B. Kamranzad, and S. Mafi, "Wind and wave energy potential in southern Caspian Sea using uncertainty analysis," Energy, vol. 120, pp. 332-345, 2017.

[15] A. A. Osinowo, X. Lin, D. Zhao, and K. Zheng, "On the Wind Energy Resource and Its Trend in the East China Sea," J. Renew. Energy, vol. 2017, 2017.

[16] D. B. P. Fabian, H. F. H. Frank, J. P. G. R. A. Hites, M. A. K. K. D. Mackay, A. H. N. J. Paasivirta, and S. H. S. P. J. Wangersky, The Handbook of Environmental Chemistry Part S / 2 Advisory Board:; vol. 5. 2008.

[17] P. Basnyat, L. D. Teeter, B. G. Lockaby, and K. M. Flynn, "The use of remote sensing and GIS in watershed level analyses of non-point source pollution problems," vol. 128, 2000.

[18] S. Mazaheri, B. Kamranzad, and F. Hajivalie, "Modification of 32 years ECMWF wind field using QuikSCAT data for wave hindcasting in Iranian Seas," no. 65, pp. 344-349, 2013.

[19] B. Kamranzad, A. Etemad-shahidi, V. Chegini, and S. Hadadpour, "Assessment of CGCM 3 . 1 wind field in the Persian Gulf," no. 65, 2013.

[20] E. Rusu and F. Onea, "Evaluation of the wind and wave energy along the Caspian Sea," Energy, vol. 50, no. 1, pp. 1-14, 2013.

[21] A. K. Azad, M. G. Rasul, and T. Yusaf, "Statistical diagnosis of the best weibull methods for wind power assessment for agricultural applications," Energies, vol. 7, no. 5, pp. 3056-3085, 2014.

[22] J. W. Twidell, Wind Turbines. .

[23] C.-D. Lai, Generalized Weibull Distributions. 2014.

[24] P. M. Ruti, S. Marullo, F. D. Ortenzio, and M. Tremant, "Comparison of analyzed and measured wind speeds in the perspective of oceanic simulations over the Mediterranean basin: Analyses, QuikSCAT and buoy data," vol. 70, pp. 33-48, 2008. 
[25] A. G. Fore, B. W. Stiles, A. H. Chau, B. A. Williams, R. S. Dunbar, and E. Rodríguez, "Point-Wise Wind Retrieval and Ambiguity Removal Improvements for the QuikSCAT Climatological Data Set," vol. 52, no. 1, pp. 51-59, 2014.

\section{Figures}

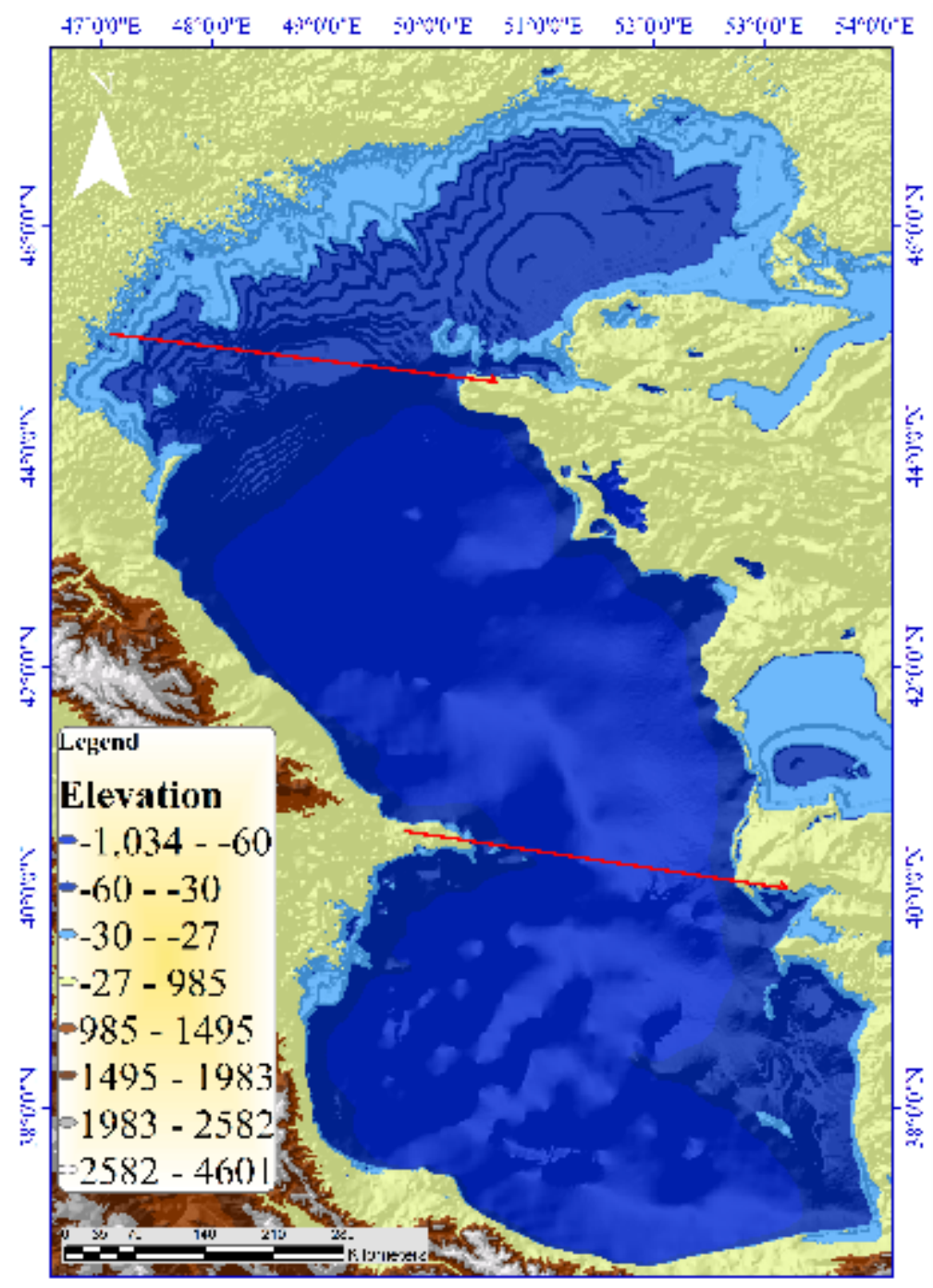

Figure 1

Position and different sections in the Caspian Sea 


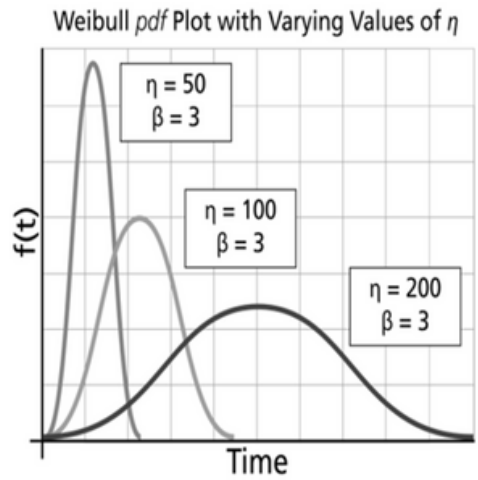

A

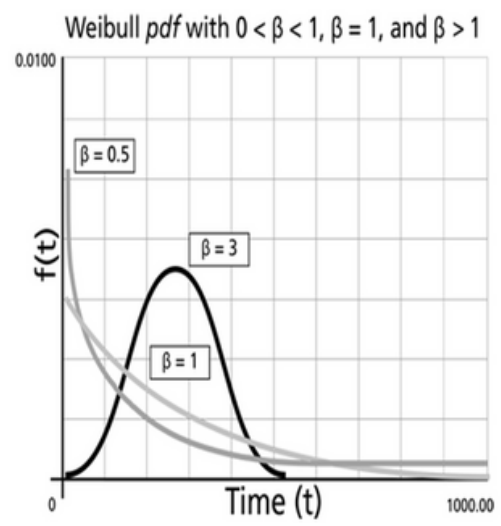

B

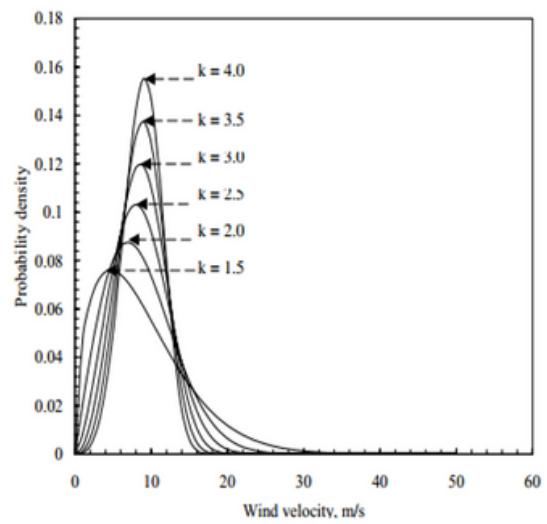

$\mathrm{C}$

\section{Figure 2}

shows the relationship of probability density with shape and scale factors.A: Effect of scale factor on probability. B:Effect of shape factor on probability curve. C: Frequency of shape and scale factors and their effect on probability function

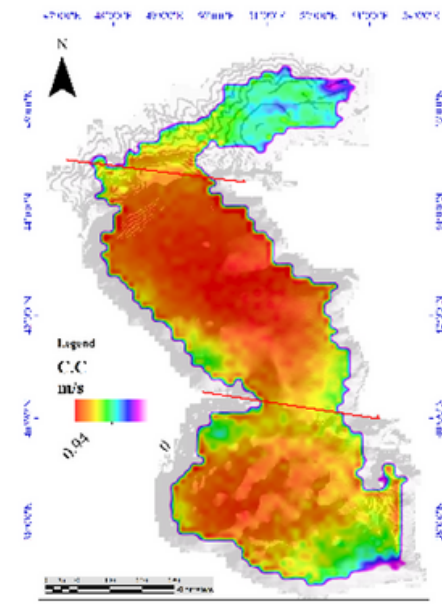

A

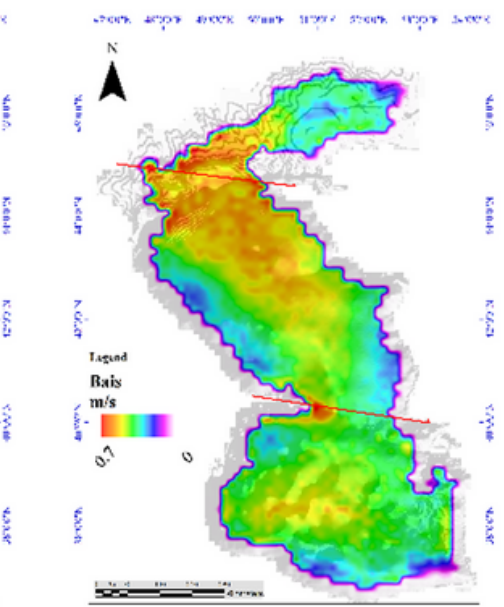

B

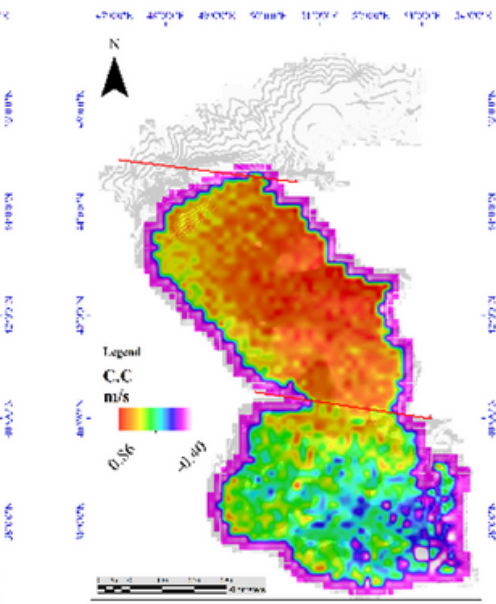

$\mathrm{C}$

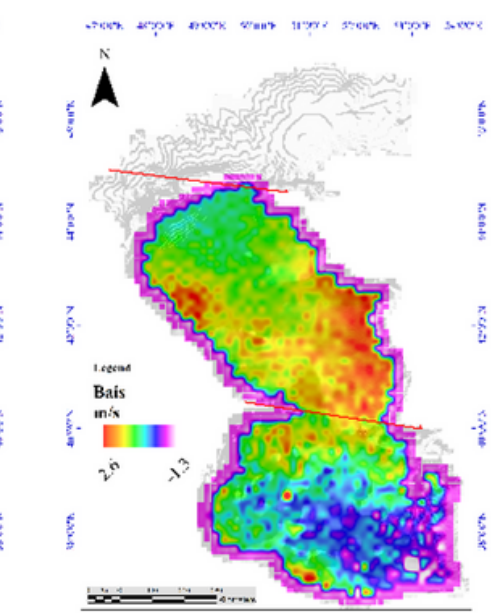

$\mathrm{D}$

\section{Figure 3}

Spatial Correlation between satallite and ERA model data for the whole period. A\&B: Respectively the Correlation and Bais of QuickScat data and the ERA-Intrem numerical model from 2000 to 2009 are shown. C\&D: Respectively the Correlation and Bais of RapidScat data and the ERA-Intrem numerical model from 2014 to 2016 are shown. 


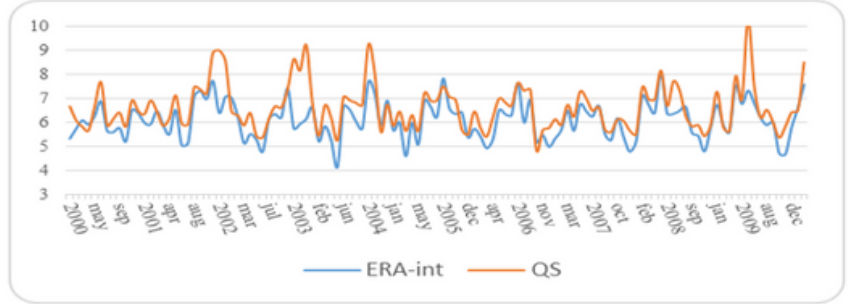

A

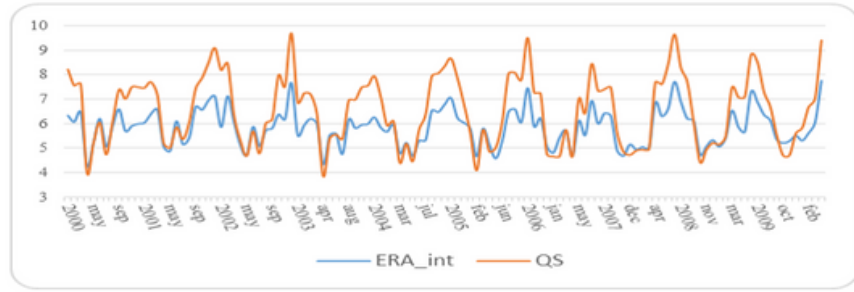

B

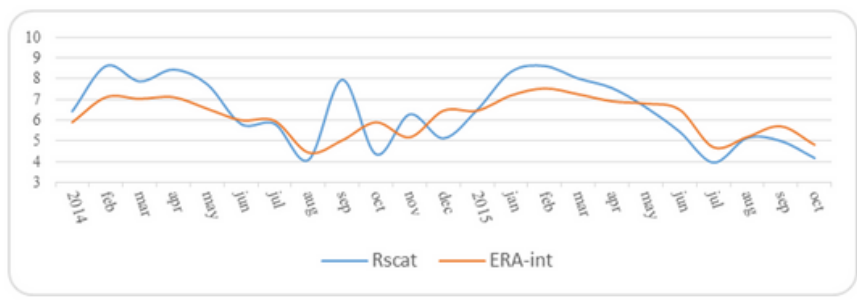

$\mathrm{D}$

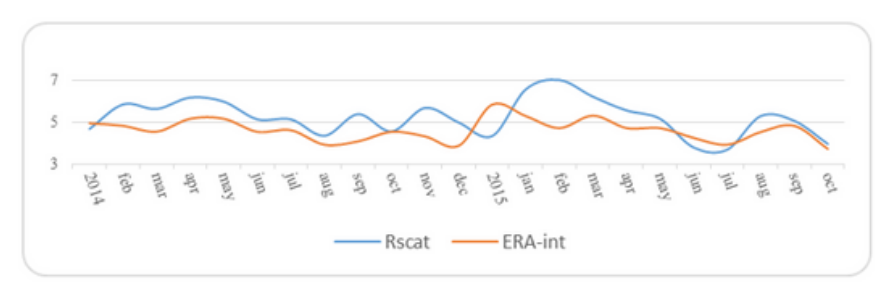

$\mathrm{E}$

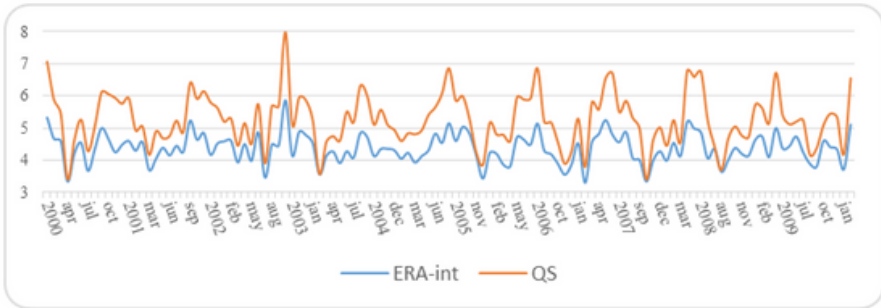

$\mathrm{C}$

\section{Figure 4}

shows A: North Caspian B: Caspian Middle S: South Caspian Time correlation of QuickScat and ERAIntrem data from 2000 to 2009. D: Caspian Middle E: South Caspian Time correlation of Rapid Scat and ERA-Intrem data from 2014 to 2016. 


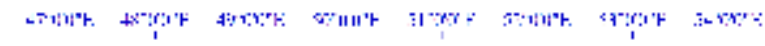

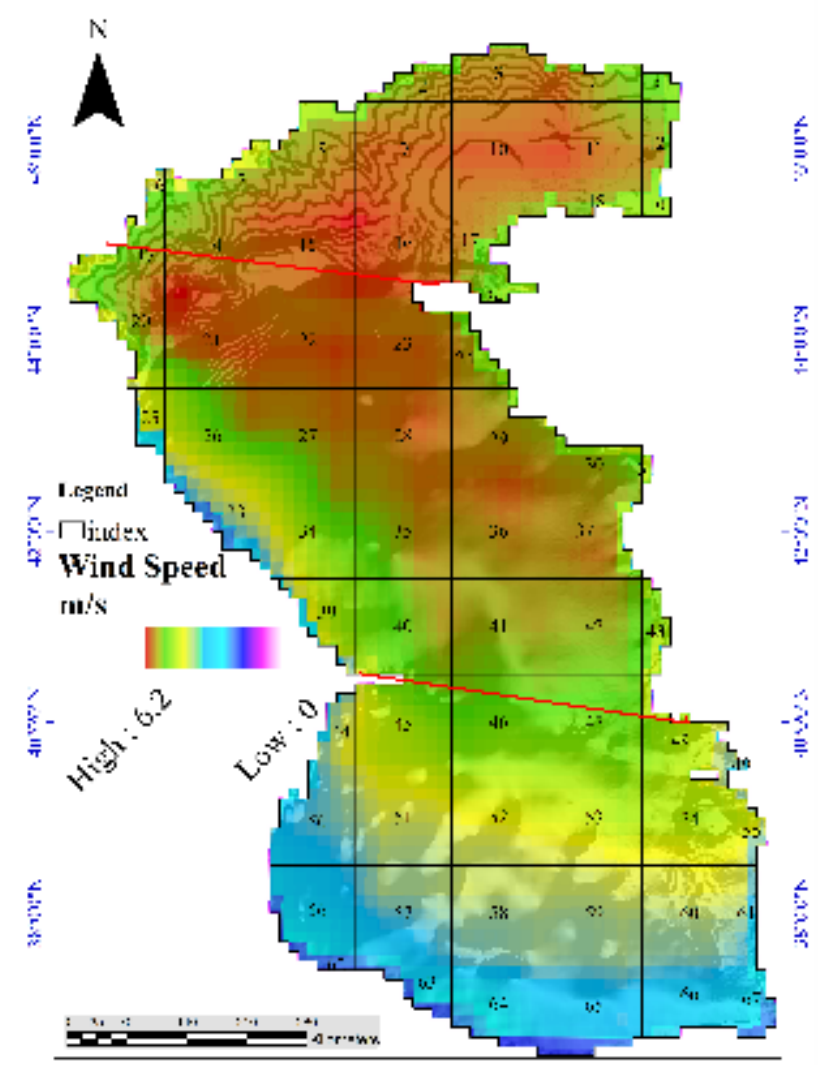

Figure 5

shows the average wind speed of 36 years (1980-2016) 

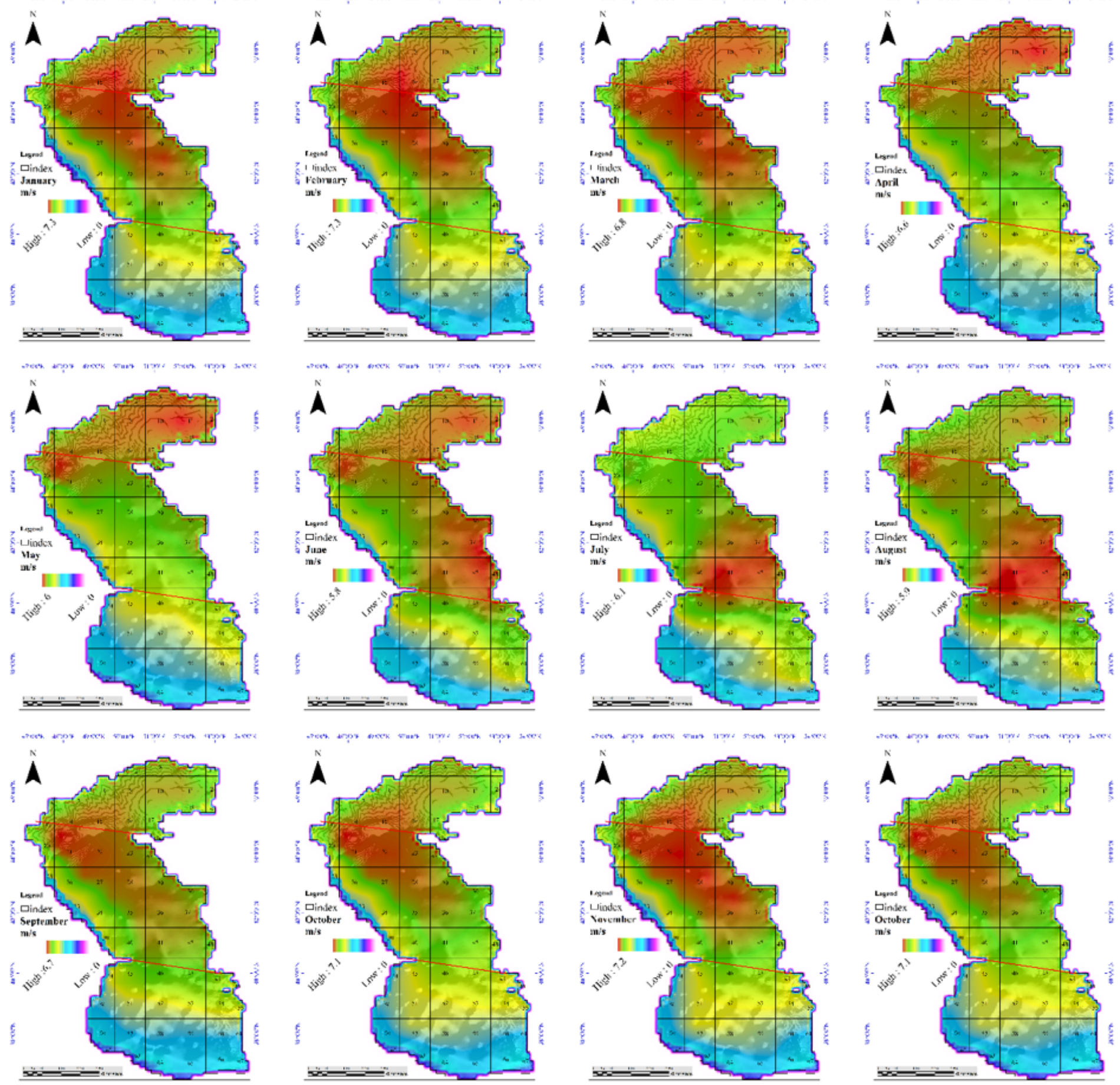

Figure 6

Monthly spatial variations of wind speed in the Caspian Sea (1980-2016) 


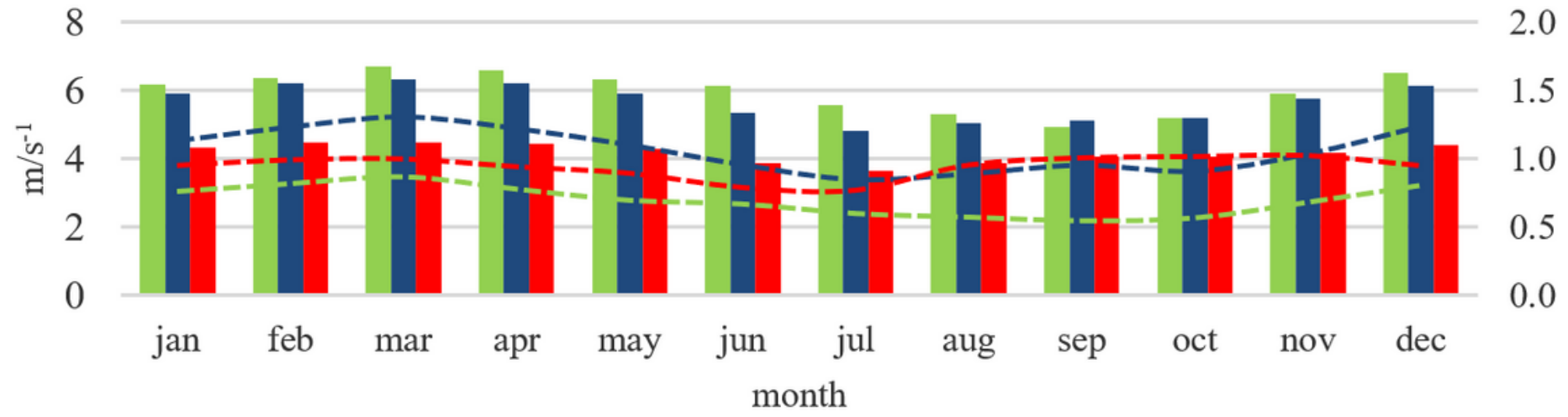

\section{Figure 7}

Monthly variations of wind speed in the Caspian Sea (1980-2016) for all parts.
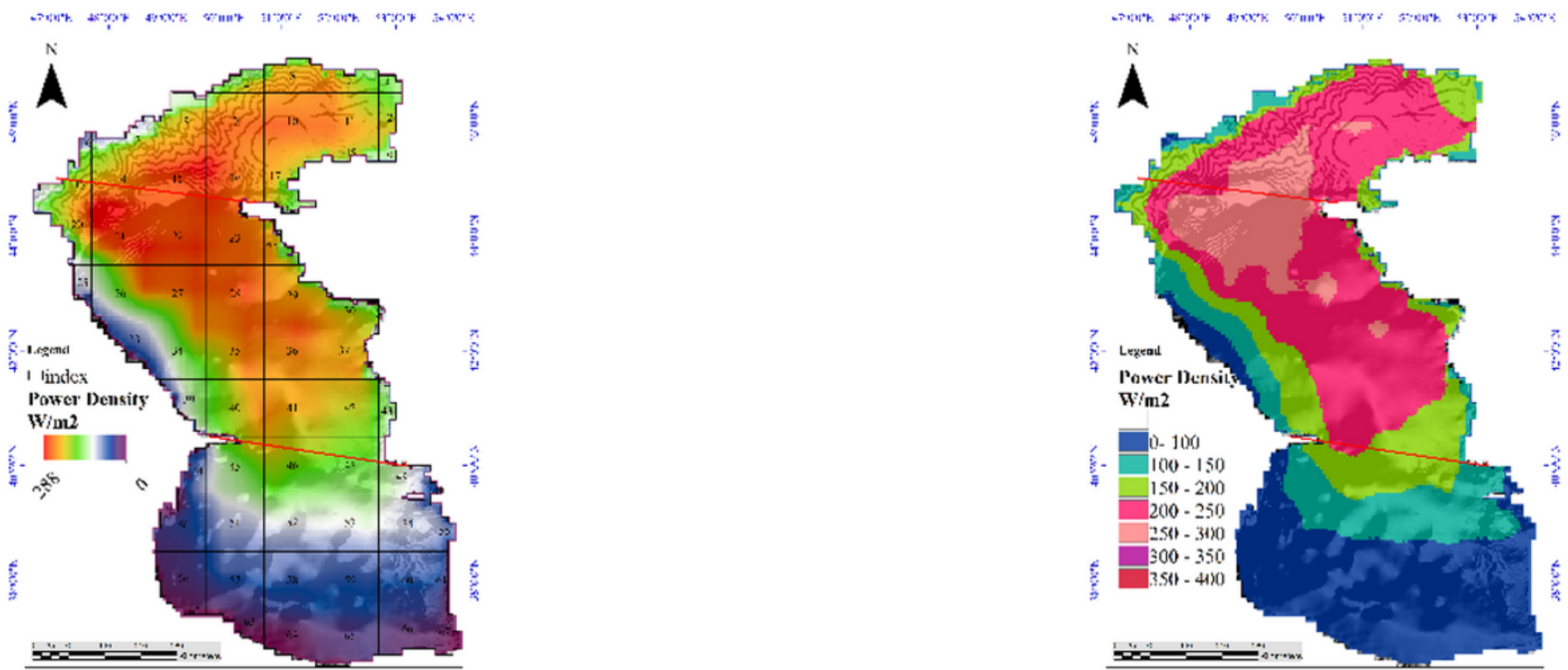

Figure 8

Power density A: Power density 2015- 2015 B: Power density classification 


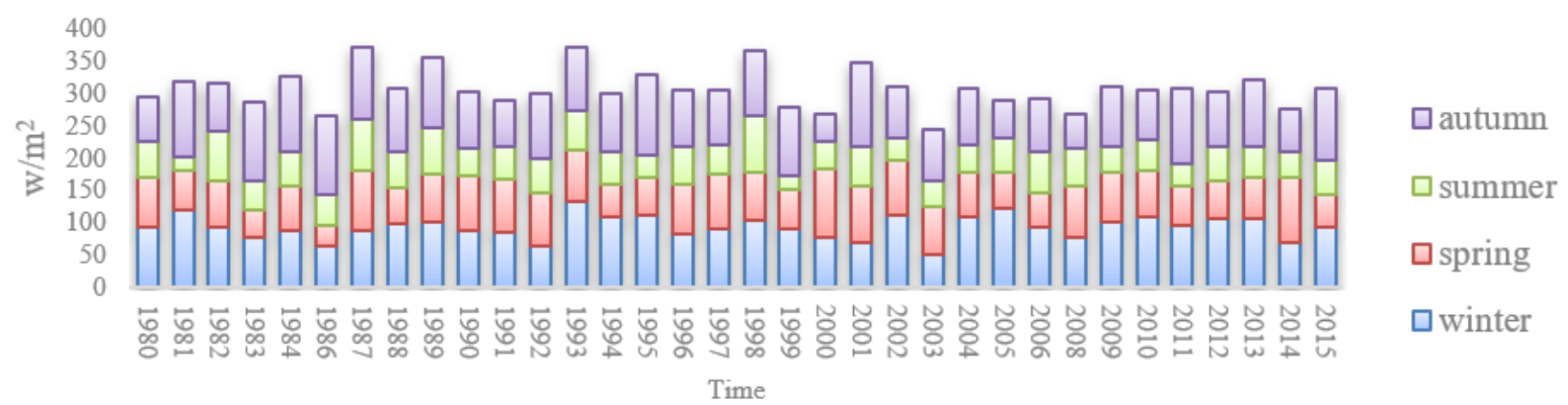

Figure 9

Seasonal variations in power density in the North Caspian Sea (1980-2015)

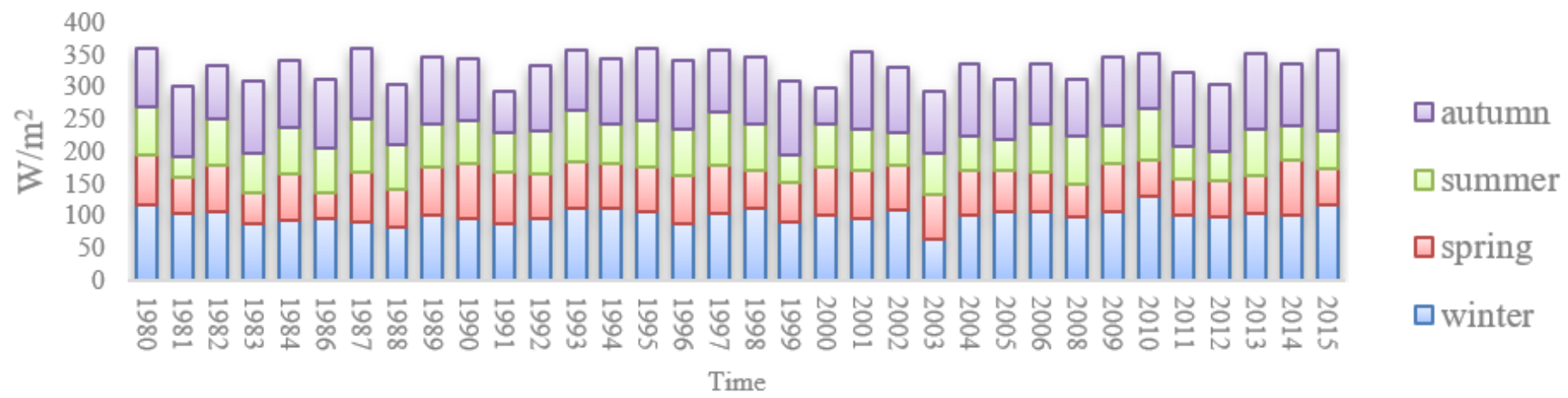

Figure 10

Seasonal variations in power density in the Mid Caspian Sea (1980-2015)

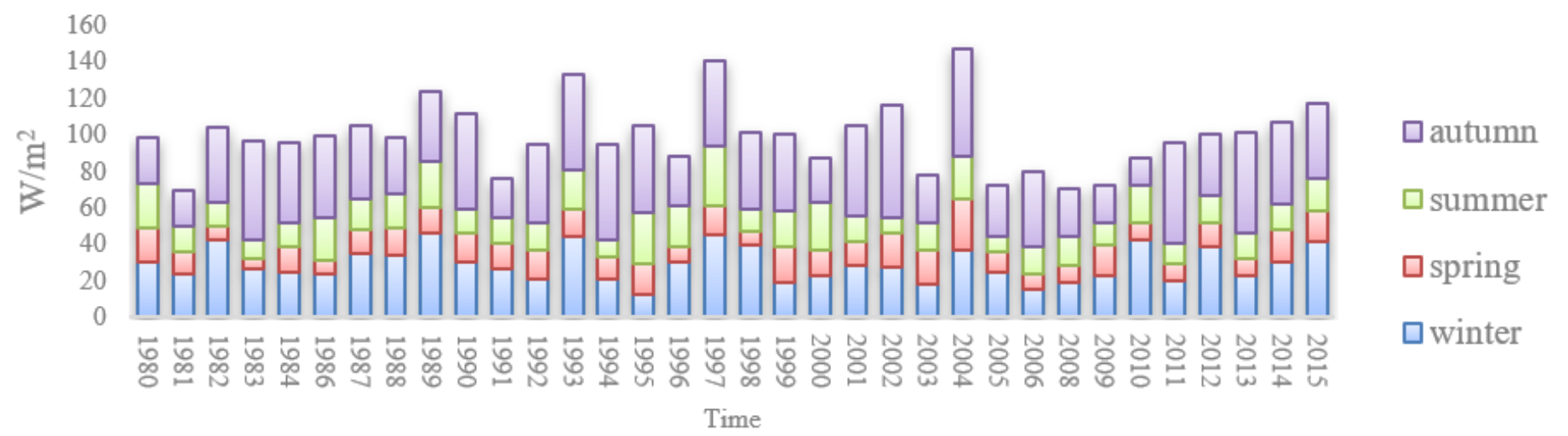

Figure 11

Seasonal variations in power density in the South Caspian Sea (1980-2015) 


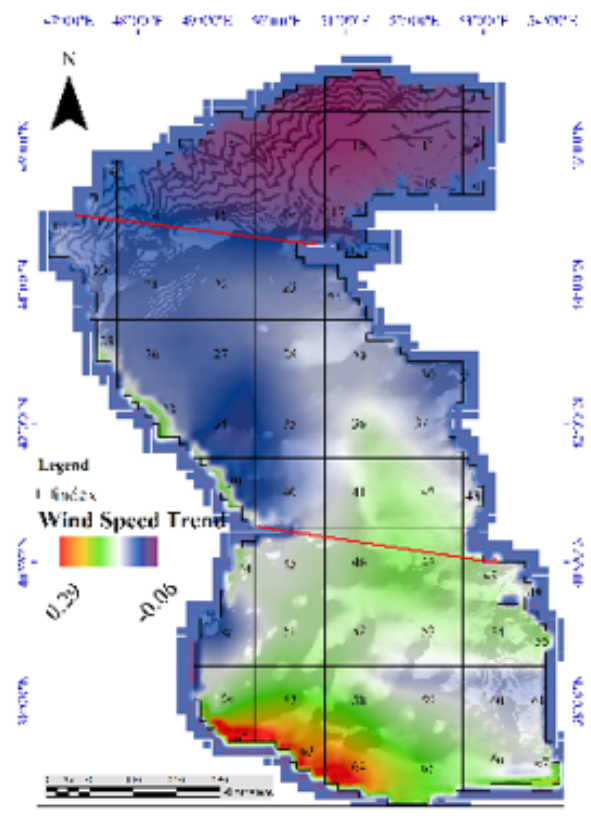

A

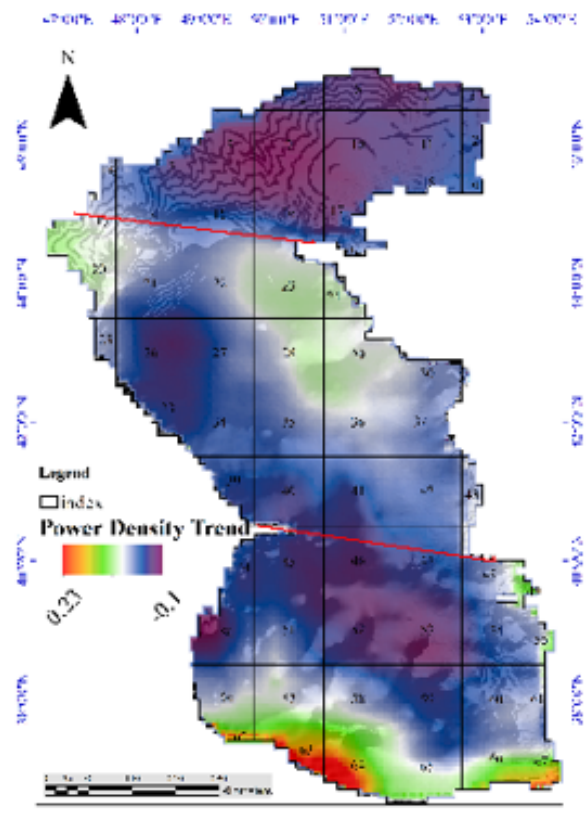

$\mathrm{D}$

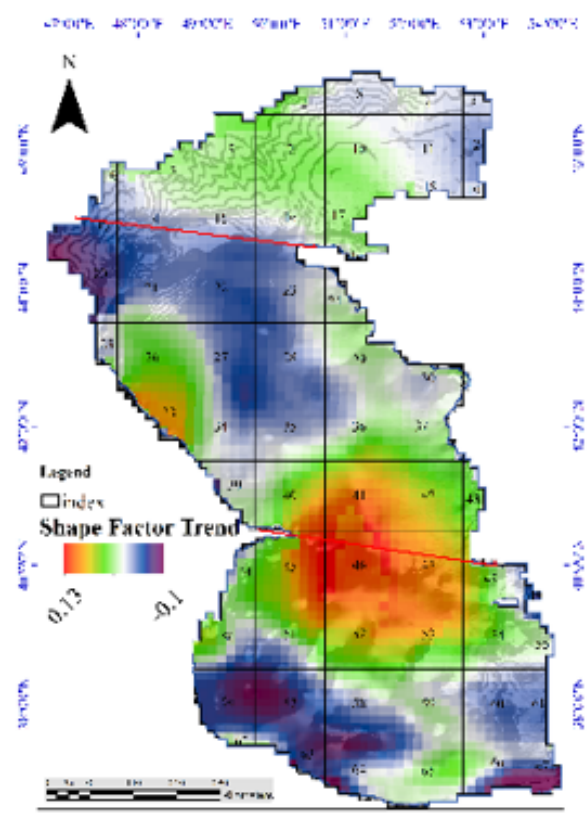

B

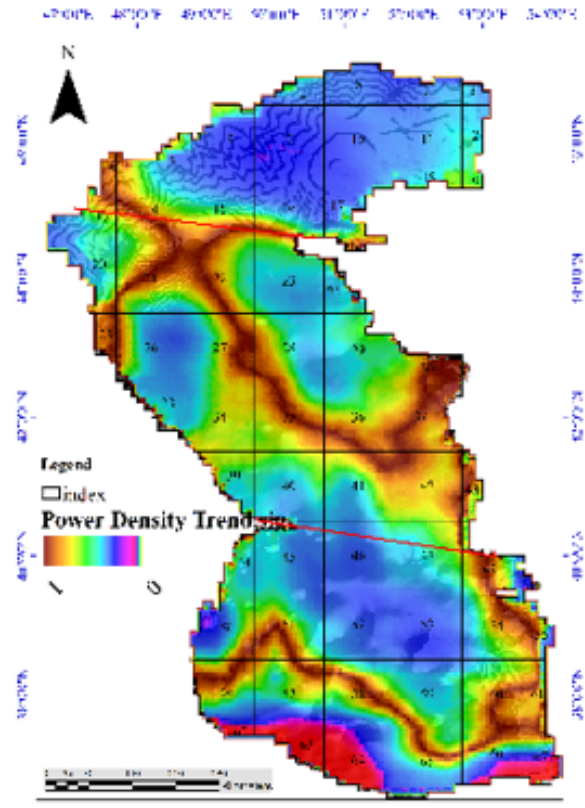

$\mathrm{E}$

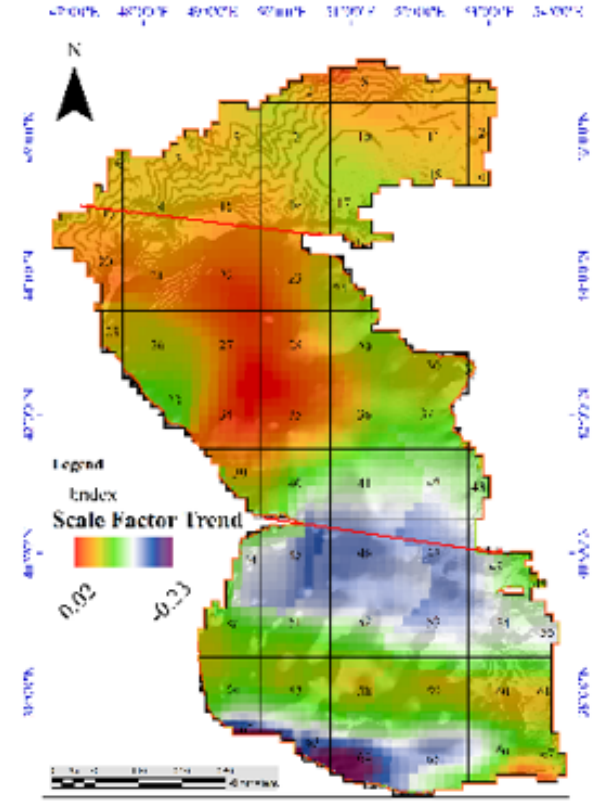

$\mathrm{C}$

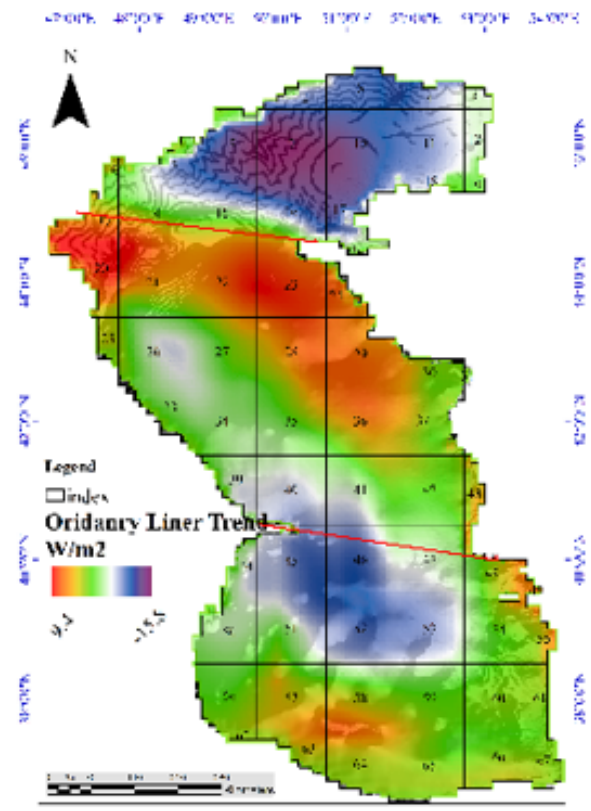

$\mathrm{F}$

Figure 12

A: Show Man-Kendall trend for wind speed, B: Show Man-Kendall trend for Shape Factor, C: Show ManKendall trend for Scale Factor, D: Show Man-Kendall trend for Power Density, E: Show Significant ManKendall trend for Power Density, F: Show Ordinary Liner trend for Power Density in (1980-2015). 


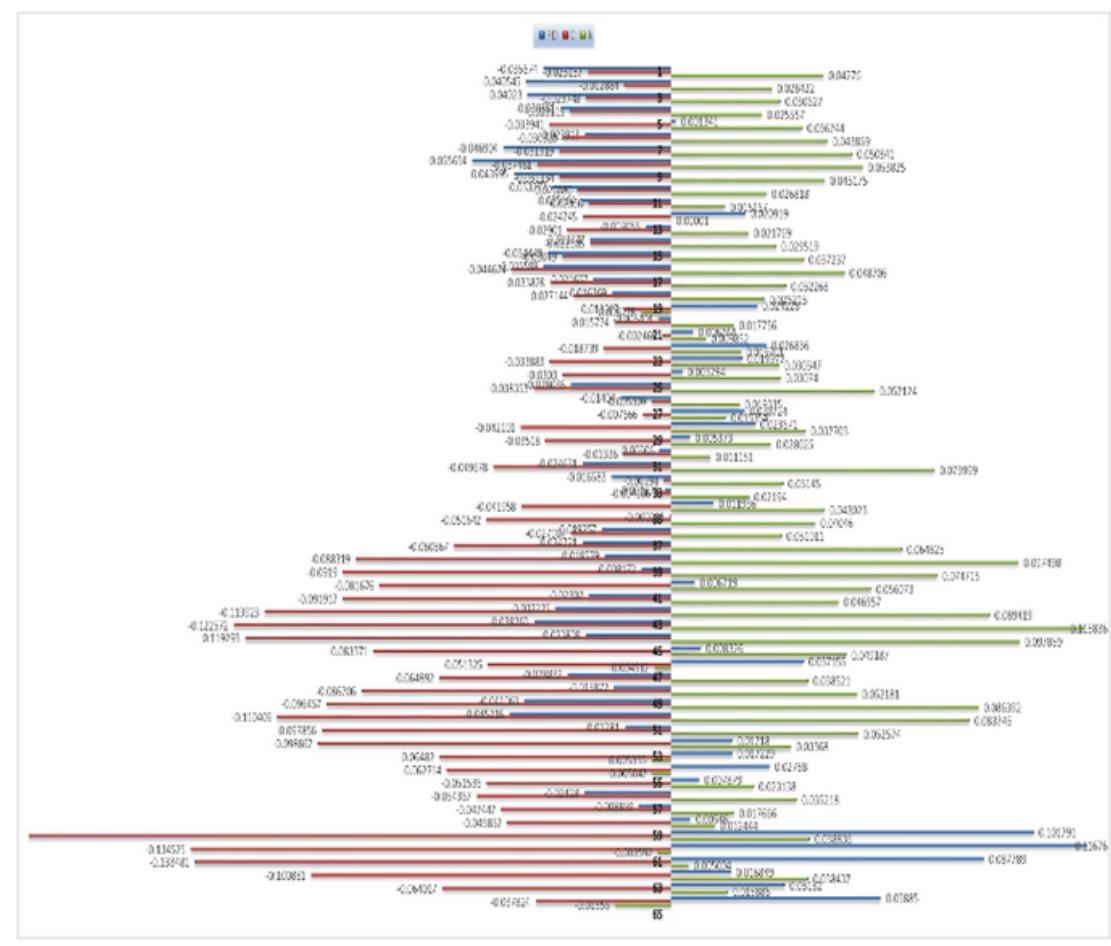

A

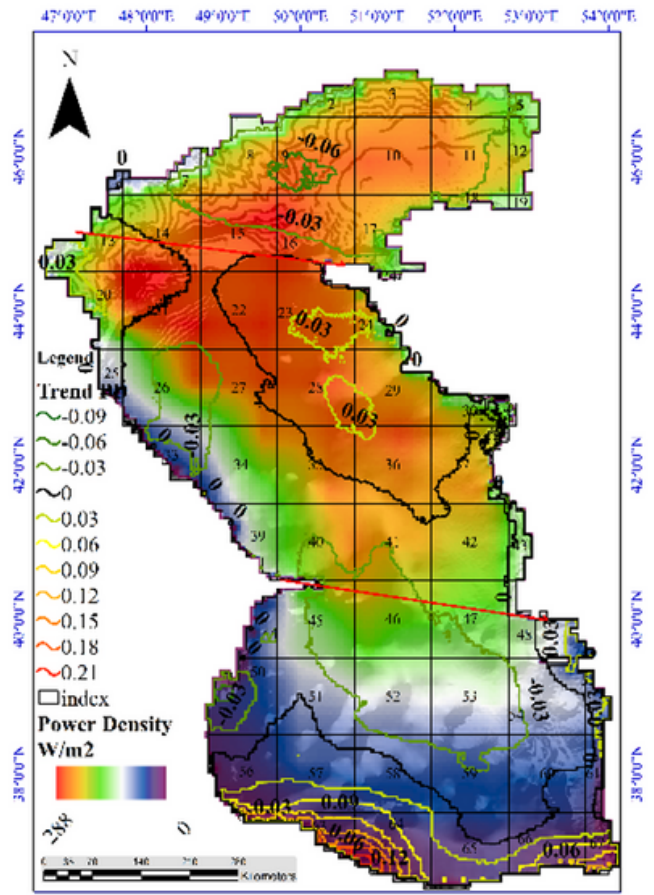

B

\section{Figure 13}

A: Represents variations in the power density trend under the influence of shape and scale factors on each profile from 1980 to 2015, B: Power density and trends of the Caspian Sea, 1980-2015.

\section{Supplementary Files}

This is a list of supplementary files associated with this preprint. Click to download.

- Highlightsoffshorewind.docx 